\title{
Surugapyrone A from Streptomyces coelicoflavus strain USF-6280 as a new DPPH radical-scavenger
}

\author{
Yasumasa Sugiyama ${ }^{1}$, Akiko Oya ${ }^{1}$, Takuji Kudo ${ }^{2}$ and Akira Hirota ${ }^{1}$ \\ Surugapyrone A, a novel 2,2-diphenyl-1-picrylhydrazyl (DPPH) radical-scavenging 2-pyrone, was isolated from the culture filtrate \\ of an actinomycete strain USF-6280. This strain was assigned to the genus Streptomyces owing to its morphological and \\ chemotaxonomic characteristics. Phylogenetic analysis based on 16S ribosomal RNA gene sequences supported the \\ classification of the producing strain as a member of the genus Streptomyces and indicated that it was closely related to \\ Streptomyces coelicoflavus. As the morphological, physiological and biochemical characteristics of the producing strain were in \\ agreement with those of the type strain of $S$. coelicoflavus, we concluded that strain USF-6280 should be identified as a \\ member of S. coelicoflavus. The structure of surugapyrone A was determined to be 4-hydroxy-6-isopropyl-3-methyl-2-pyrone on \\ the basis of the spectroscopic data. The results of feeding experiments with ${ }^{13} \mathrm{C}$-labeled compounds indicated that surugapyrone \\ A was biosynthesized through a polyketide pathway involving isobutyrate, acetate and propionate.
}

The Journal of Antibiotics (2010) 63, 365-369; doi:10.1038/ja.2010.60; published online 30 June 2010

Keywords: 4-hydroxy-2-pyrone; DPPH radical-scavenging activity; polyketide biosynthetic pathway; Streptomyces sp.; surugapyrone

\section{INTRODUCTION}

During the course of screening for antioxidants from microbial metabolites, our research group isolated several interesting 2,2-diphenyl-1-picrylhydrazyl (DPPH) radical-scavenging compounds. ${ }^{1-6}$ Recently, we found that Streptomyces sp. strain USF-6280 obtained from a soil sample collected in Suruga-ku, Shizuoka-city, Japan, produced two new DPPH radical-scavenging $N$-hydroxypyrrole compounds-surugapyrroles A and B. ${ }^{7}$ Furthermore, from the same microorganism strain we isolated a new 4-hydroxy-2-pyrone compound-surugapyrone A-that has DPPH radical-scavenging activity.

This paper describes taxonomic characterization and identification of the producing strain, and cultivation, isolation, structure elucidation and biosynthesis of surugapyrone $\mathrm{A}$.

\section{RESULTS}

Taxonomy of the producing strain

The strain USF-6280 grew well on all media tested; that is, yeast extract-malt extract agar (ISP 2), oatmeal agar (ISP 3), inorganic saltsstarch agar (ISP 4), yeast-starch agar (YS), V8 juice agar (V8), Bennett's agar and Gauze's synthetic medium no. 1. Pale gray aerial mycelia were produced on ISP 2 , ISP 3 , ISP 4 , YS and V8, and the vegetative mycelia were orange to yellow or pale brown on all the media tested. No melanoid pigments were produced in the peptoneyeast extract-iron agar (ISP 6) and tyrosine agar (ISP 7), and no other soluble pigments were produced in any of the media tested. Detailed physiological results are given in Table 1. The strain USF-6280 formed open spiral chains consisting of $>50$ spores with smooth surfaces on the aerial hyphae (Figure 1) and was found to contain LL- $\mathrm{A}_{2} \mathrm{pm}$ as the diamino acid of the peptidoglycan. An almost-complete $16 \mathrm{~S}$ ribosomal RNA (rRNA) gene of strain USF-6280 with a length of $1478 \mathrm{bp}$ was amplified by using PCR and sequenced and aligned with the corresponding sequences of selected organisms obtained from the DDBJ (DNA Data Bank of Japan, Shizuoka, Japan). A neighborjoining tree is shown in Figure 2.

\section{Cultivation of strain USF-6280}

The strain USF-6280 was cultivated on a reciprocal shaker for 4 days at $30{ }^{\circ} \mathrm{C}$ in $0.5-1$ flasks each containing $100 \mathrm{ml}$ of a medium consisting of glucose $1 \%$, polypeptone $0.2 \%$, meat extract $0.1 \%$, yeast extract $0.1 \%$, adjusted at $\mathrm{pH} 7.2$.

\section{Isolation of compound 1}

The culture broth of strain USF-6280 (101) was filtered and the culture filtrate was extracted with EtOAc at $\mathrm{pH} 3$. The resulting extract was concentrated and applied to a silica gel column eluted with $n$-hexane-EtOAc. The $n$-hexane/EtOAc (1:1) eluate fraction showed DPPH radical-scavenging activity in the TLC assay. ${ }^{8}$ This fraction was further applied to a silica gel column and eluted with $n$-hexane/EtOAc $(2: 1)$. The active fraction was purified by repeated Sephadex LH-20 column chromatography $(\mathrm{MeOH})$, and the fraction containing DPPH

${ }^{1}$ School of Food and Nutritional Sciences, University of Shizuoka, Yada, Suruga-ku, Shizuoka, Japan and ${ }^{2}$ Japan Collection of Microorganisms, RIKEN BioResource Center, Hirosawa, Wako, Saitama, Japan

Correspondence: Dr Y Sugiyama, Laboratory of Applied Microbiology, School of Food and Nutritional Sciences, University of Shizuoka, 52-1 Yada, Suruga-ku, Shizuoka 422-8526, Japan.

E-mail: sugiyasu@u-shizuoka-ken.ac.jp

Received 15 March 2010; revised 17 May 2010; accepted 24 May 2010; published online 30 June 2010 
Table 1 Comparison of morphological, cultural and physiological characteristics between strain USF-6280 and the type strain of Streptomyces coelicoflavus (JCM $6918^{\mathrm{T}}$ )

\begin{tabular}{lcc}
\hline Characteristic & $\begin{array}{c}\text { Strain } \\
\text { USF-6280 }\end{array}$ & $\begin{array}{c}\text { S. coelicoflavus } \\
\text { JCM } 6918^{T}\end{array}$ \\
\hline Color of aerial mycelia on ISP 3 & Pale gray & Pale gray \\
Color of vegetative mycelia in ISP 3 & Yellow-orange & Yellow-orange \\
Production of soluble pigments & - & - \\
Production of melanoid pigments & - & - \\
Spore chains & Spiral & Spiral \\
Spore surface & Smooth & Smooth \\
& & \\
Utilization of & & ++ \\
Arabinose & ++ & ++ \\
D-Glucose & ++ & ++ \\
Fructose & ++ & ++ \\
Inositol & ++ & ++ \\
Mannose & ++ & ++ \\
Raffinose & ++ & ++ \\
Rhamnose & ++ & + \\
Sucrose & - & ++ \\
Xylose & ++ & \\
\hline
\end{tabular}

radical-scavenging compounds was purified using preparative ODS HPLC $\left(\mathrm{CH}_{3} \mathrm{CN}-\mathrm{H}_{2} \mathrm{O}\right.$-TFA). Finally, compound $\mathbf{1}$ was isolated as colorless needles together with a mixture containing other related compounds; yield, $49.1 \mathrm{mg}$.

\section{Structure elucidation}

The molecular formula of 1 was determined to be $\mathrm{C}_{9} \mathrm{H}_{12} \mathrm{O}_{3}$ by the pseudomolecular ion $[\mathrm{M}+\mathrm{H}]^{+}$(found $\mathrm{m} / \mathrm{z}$ 169.0874, calcd. for $\mathrm{C}_{9} \mathrm{H}_{13} \mathrm{O}_{3} \mathrm{~m} / z$ 169.0865) of the HR FAB-MS. In the UV spectrum of 1, an absorption maximum was observed at $287 \mathrm{~nm}$ (Table 2), suggesting the presence of a 2-pyrone moiety. ${ }^{9,10}$ In the ${ }^{1} \mathrm{H}$-NMR spectrum of 1 (Table 3 ), the proton signals observed include two overlapping doublet methyl signals, a singlet methyl signal, a septet methine signal and an olefinic signal. This spectrum therefore indicates the presence of one methyl group, one isopropyl group and one trisubstituted olefin in the structure of $\mathbf{1}$. As only eight carbon signals were observed in the ${ }^{13} \mathrm{C}$-NMR spectrum of $\mathbf{1}$ (Table 3 ), it seems that the expected carbon signal at $\delta 20.3$ overlaps with the two methyl carbon signals from the isopropyl group. The HMBC spectrum showed a number of cross-peaks. These cross-peaks were visible between the singlet methyl proton at $\delta 1.85\left(3-\mathrm{CH}_{3}\right)$ and the three carbon signals ( $\delta 98.9(\mathrm{C}-3), 167.9(\mathrm{C}-4)$ and $169.0(\mathrm{C}-2)$ ), between the methyl protons of the isopropyl group at $\delta 1.22\left(\mathrm{H}-2^{\prime}\right.$ and $\left.1^{\prime}-\mathrm{CH}_{3}\right)$
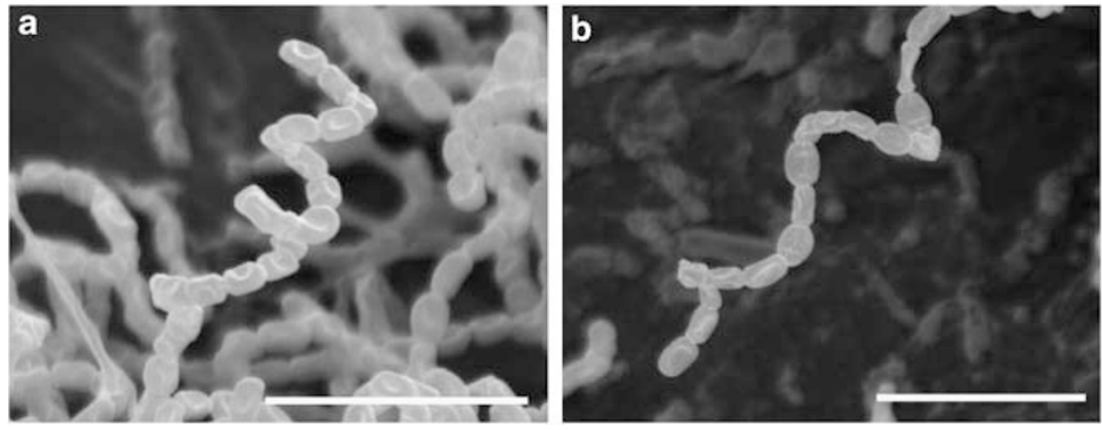

Figure 1 Scanning electron micrograph of strains USF-6280 (a) and Streptomyces coelicoflavus JCM 6918 ${ }^{\top}$ (b) grown on oatmeal agar (ISP 3 ) for 14 days at $28^{\circ} \mathrm{C}$. The scale bar indicates $5 \mu \mathrm{m}(\mathbf{a}, \mathbf{b})$.

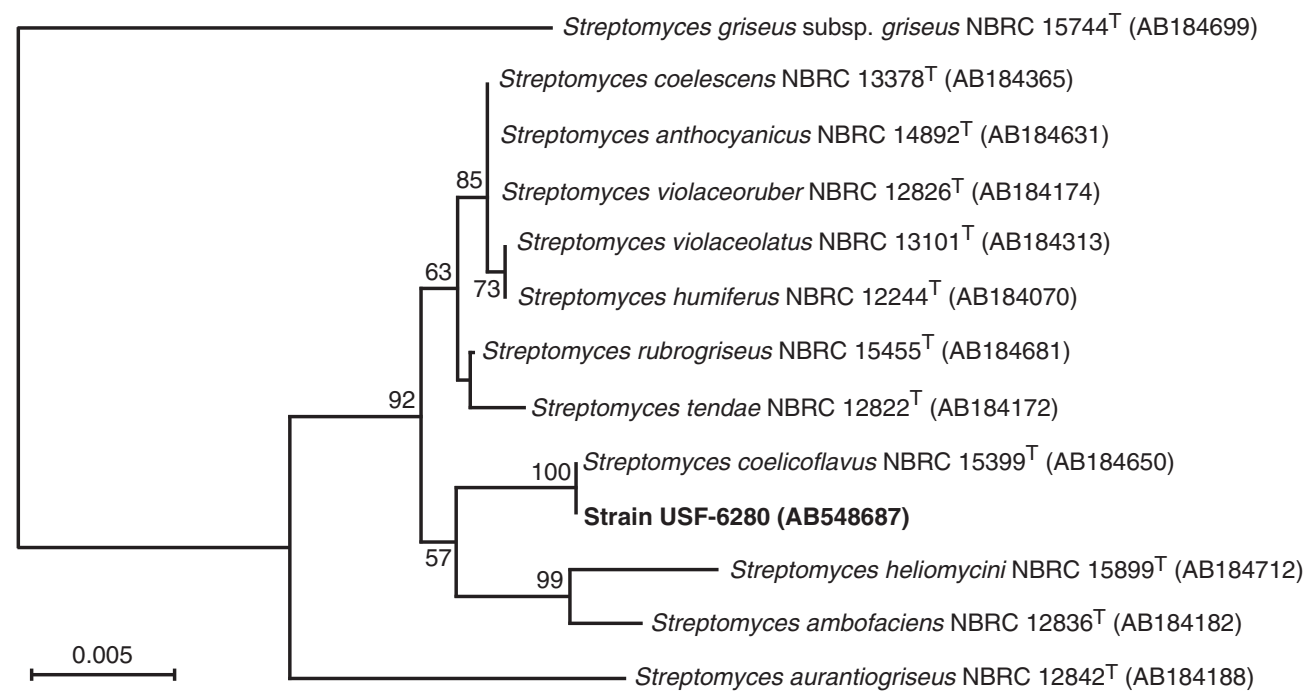

Figure 2 Neighbor-joining tree based on 16S rRNA gene sequences obtained from the DDBJ database (accession numbers are given in parentheses) showing the position of strain USF-6280. Percentage bootstrap values based on 1000 replications are given at branch points (only values over $50 \%$ are given). The scale bar indicates 0.005 substitutions per nucleotide position. 
Table 2 Pysicochemical properties of surugapyrone A (1)

\begin{tabular}{lc}
\hline Appearance & Colorless needles \\
Molecular weight & 168 \\
Molecular formula & $\mathrm{C}_{9} \mathrm{H}_{12} \mathrm{O}_{3}$ \\
$\mathrm{Mp}\left({ }^{\circ} \mathrm{C}\right)$ & $191-193$ \\
& \\
$H R$ FAB-MS $(\mathrm{m} / \mathrm{z})$ & \\
Found: & $169.0874[\mathrm{M}+\mathrm{H}]^{+}$ \\
Calcd.: & 169.0865 \\
$\mathrm{IR} v_{\max }(\mathrm{KBr})$ & $2980,2930,2690,1650$, \\
& $1580,1410,1240,1160$ \\
UV $\lambda \max (\mathrm{MeOH}) \mathrm{nm}(\varepsilon)$ & $287(8760), 206(9879)$ \\
\hline
\end{tabular}

Table 3 NMR spectral data for surugapyrone $A(1)$ in $C_{3} O D$

\begin{tabular}{lrcc}
\hline Position & $\delta_{C^{\mathrm{a}}}$ & $\delta_{\left.H^{\mathrm{b}} \text { (integral, mult., J }(\mathrm{Hz})\right)}$ & $\mathrm{H} M B C^{\mathrm{C}}$ \\
\hline 2 & 169.0 & - & \\
3 & 98.9 & - & \\
4 & 167.9 & - & $\mathrm{C}-3, \mathrm{C}-4, \mathrm{C}-6, \mathrm{C}-1^{\prime}$ \\
5 & 98.7 & $5.99(1 \mathrm{H}, \mathrm{s})$ & \\
6 & 169.4 & - & $\mathrm{C}-2, \mathrm{C}-3, \mathrm{C}-4$, \\
$3-\mathrm{CH}_{3}$ & 8.2 & $1.58(3 \mathrm{H}, \mathrm{s})$ & $\mathrm{C}-5, \mathrm{C}-6, \mathrm{C}-2^{\prime}, \mathrm{1}^{\prime}-\mathrm{CH}_{3}$ \\
$1^{\prime}$ & 33.5 & $2.72(1 \mathrm{H}, \mathrm{sept})$ & $\mathrm{C}-6, \mathrm{C}-1^{\prime}, \mathrm{C}-2^{\prime}, 1^{\prime}-\mathrm{CH}_{3}$ \\
$2^{\prime}, 1^{\prime}-\mathrm{CH}_{3}$ & $20.3^{\mathrm{d}}$ & $1.22(6 \mathrm{H}, \mathrm{d}, \mathrm{J}=7.4 \mathrm{~Hz})^{\mathrm{d}}$ & \\
\hline
\end{tabular}

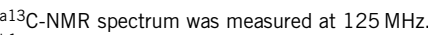

${ }^{61} \mathrm{H}-\mathrm{NMR}$ spectrum was measured at $500 \mathrm{MHz}$.

CHMBC correlations optimized for $8 \mathrm{~Hz}$ are from proton started to the indicated carbons.

dSignal overlappings.<smiles>Cc1c(O)cc(C(C)(C)C)oc1=O</smiles>

surugapyrone $\mathrm{A}(\mathbf{1})$

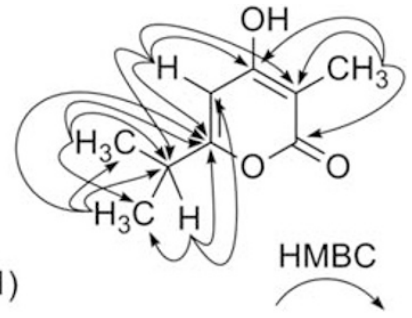

Figure 3 Structure and HMBC spectral data for surugapyrone A (1).

and the two carbon signals $\left(\delta 33.5\left(\mathrm{C}-1^{\prime}\right)\right.$ and $\left.169.4(\mathrm{C}-6)\right)$, between the methine proton of the isopropyl group at $\delta 2.72\left(\mathrm{H}-1^{\prime}\right)$ and the three carbon signals $\left(\delta 20.3\left(\mathrm{C}-2^{\prime}\right.\right.$ and $\left.1^{\prime}-\mathrm{CH}_{3}\right), 98.7(\mathrm{C}-5)$ and 169.4 $(\mathrm{C}-6))$, and between the olefinic proton at $\delta 5.99(\mathrm{H}-5)$ and the four carbon signals $\left(\delta 33.5\left(\mathrm{C}-1^{\prime}\right), 98.9(\mathrm{C}-3), 167.9(\mathrm{C}-4)\right.$ and 169.4 (C-6)). These data confirm the identity of 1 to be 4-hydroxy-6isopropyl-3-methyl-2-pyrone (Figure 3). As this compound is a novel, we named it 'surugapyrone A'.

\section{DPPH radical-scavenging activity}

Surugapyrone A (1) had an $\mathrm{ED}_{50}$ value of $500 \mu \mathrm{M}$ as determined by the $\mathrm{DPPH}$ radical-scavenging activity assay after standing for $5 \mathrm{~h}$. In the case of the short reaction time of $30 \mathrm{~min}$, the $\mathrm{ED}_{50}$ value of 1 was shown to be $4.2 \mathrm{~mm}$, and the DPPH radical-scavenging activity of 1 is therefore mild as compared with that of the positive control butylated hydroxytoluene $\left(\mathrm{ED}_{50}: 33.8 \mu \mathrm{M}\right)$.

Biosynthesis of surugapyrone A (1)

Production of surugapyrone A (1) was initiated approximately $48 \mathrm{~h}$ after inoculation under the culture conditions of this study, and it
Table $4{ }^{13} \mathrm{C}$ abundance in surugapyrone $\mathrm{A}(1)$ obtained from the feeding experiments with ${ }^{13} \mathrm{C}$ labeled precursors

\begin{tabular}{|c|c|c|c|c|}
\hline \multirow[b]{2}{*}{ Position } & \multirow[b]{2}{*}{$\delta_{C}{ }^{a}$} & \multicolumn{3}{|c|}{ Relative ${ }^{13} \mathrm{C}$ abundance } \\
\hline & & $\begin{array}{l}{\left[1-{ }^{13} C\right]} \\
\text { acetate }^{b}\end{array}$ & $\begin{array}{c}{\left[1-{ }^{13} \mathrm{C}\right]} \\
\text { propionate }^{c}\end{array}$ & $\begin{array}{c}{\left[1-{ }^{13} \mathrm{C}\right]} \\
\text { isobutyrate }\end{array}$ \\
\hline 2 & 169.0 & 1.5 & 26.3 & 1.0 \\
\hline 3 & 98.9 & 0.9 & 0.4 & 0.8 \\
\hline 4 & 167.9 & 4.6 & 0.6 & 0.7 \\
\hline 5 & 98.7 & 1.1 & 0.9 & 1.2 \\
\hline 6 & 169.4 & 1.0 & 1.0 & 1.5 \\
\hline $3-\mathrm{CH}_{3}$ & 8.2 & 1.1 & 1.0 & 1.1 \\
\hline $1^{\prime}$ & 33.5 & 1.1 & 1.2 & 1.1 \\
\hline $2^{\prime}, 1^{\prime}-\mathrm{CH}_{3}$ & 20.3 & 1.0 & 1.0 & 1.0 \\
\hline
\end{tabular}

In $\mathrm{CD}_{3} \mathrm{OD}$

b $\left[1-{ }^{13} \mathrm{C}\right]$ sodium acetate.

${ }^{\mathrm{C}}\left[1-{ }^{13} \mathrm{C}\right]$ sodium propionate.

d $\left[1-{ }^{13} \mathrm{C}\right]$ isobutyric acid.

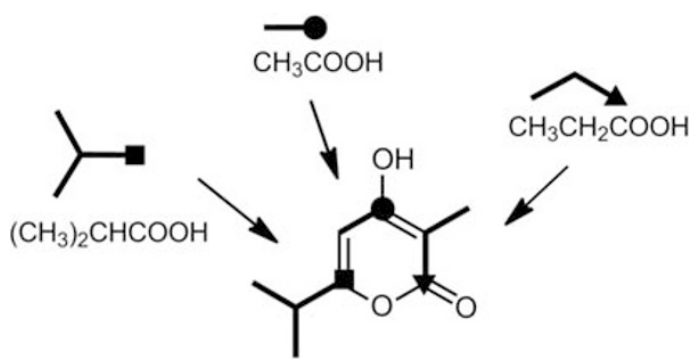

Figure 4 Biosynthetic origin of surugapyrone A (1)

increased up to $96 \mathrm{~h}$; the amount of 1 in the medium remained constant between 96 and $144 \mathrm{~h}$. Surugapyrone A (1) (ca $0.5 \mathrm{mg}$ ) was yielded from $100 \mathrm{ml}$ of the culture broth after $120 \mathrm{~h}$. Therefore, a biosynthetic study on surugapyrone A (1) was undertaken by conducting feeding experiments with a variety of ${ }^{13} \mathrm{C}$-labeled compounds. Five ${ }^{13} \mathrm{C}$-labeled compounds, namely, $\left[1-{ }^{13} \mathrm{C}\right]$ sodium acetate, $\left[1-{ }^{13} \mathrm{C}\right]$ sodium butyrate, $\left[1-{ }^{13} \mathrm{C}\right]$ sodium propionate, $\left[1-{ }^{13} \mathrm{C}\right]$ isobutyric acid and $\mathrm{L}-\left[\right.$ methyl $\left.-{ }^{13} \mathrm{C}\right]$ methionine, were separately added to the fermentation broth of $S$. coelicoflavus strain USF-6280, which had been cultured in a medium for $48 \mathrm{~h}$ at $30^{\circ} \mathrm{C}$; the derived media were then incubated for an additional $72 \mathrm{~h}$.

In the feeding experiment with $\left[1-{ }^{13} \mathrm{C}\right]$ sodium acetate, only the $\mathrm{C}-4$ carbon signal was enriched in the ${ }^{13} \mathrm{C}-\mathrm{NMR}$ spectrum of 1 . In the subsequent experiment with $\left[1-{ }^{13} \mathrm{C}\right]$ sodium propionate, only the $\mathrm{C}-2$ carbon signal was enriched in the ${ }^{13} \mathrm{C}-\mathrm{NMR}$ spectrum of the ${ }^{13} \mathrm{C}$ labeled 1. Furthermore, in the feeding experiment with $\left[1-{ }^{13} \mathrm{C}\right]$ isobutyric acid, the C-6 carbon signal was enriched in the ${ }^{13} \mathrm{C}-\mathrm{NMR}$ spectrum (Table 4). In contrast, the results of the feeding experiments with $\left[1-{ }^{13} \mathrm{C}\right]$ sodium butyrate and $\mathrm{L}-\left[\right.$ methyl $\left.-{ }^{13} \mathrm{C}\right]-$ methionine indicated that butyric acid and methionine were not incorporated in $\mathbf{1}$. Thus, these feeding experiments revealed that C-4 and C-5 of 1 were derived from acetate; C-2, C-3 and C-3-methyl, from propionate; and $\mathrm{C}-6, \mathrm{C}-1^{\prime}, \mathrm{C}-2^{\prime}$ and $1^{\prime}-\mathrm{CH}_{3}$, from isobutyrate (Figure 4). Hence, we determined the origin of all the carbon atoms of $\mathbf{1}$ and found that its biosynthesis involves the polyketide pathway.

\section{DISCUSSION}

The strain USF-6280 has morphological characteristics that were consistent with members of the genus Streptomyces. The biochemical 
composition of the cell wall supported the classification of this strain as a member of this genus. The $16 \mathrm{~S}$ rRNA gene analysis showed that the sequences of strain USF-6280 and the type strain of Streptomyces coelicoflavus were completely identical (Figure 2). The cultural, physiological and biochemical characteristics of strain USF-6280 were also in agreement with those of the type strain of $S$. coelicoflavus as shown in Table 1. On the basis of the phenotypic and phylogenetic data, it was concluded that the strain USF-6280 should be identified as a member strain of $S$. coelicoflavus.

Surugapyrone A(1), a 4-hydroxy-2-pyrone, from S. coelicoflavus strain USF-6280 was characterized as a new, small molecule with mild DPPH radical-scavenging activity. The mild activity of surugapyrone A is similar to that of the two 4-hydroxy-2-pyrones previously isolated from fungi by our research group. ${ }^{4,11}$ Accordingly, the mechanism of the DPPH radical-scavenging of 1 was expected to proceed through formation of an adduct with the DPPH radical. ${ }^{4,11}$

Recently, the biosynthesis of similar 2-pyrone derivatives isolated from Streptomyces coelicolor was studied mainly by means of LC/MS analysis. ${ }^{12}$ Our results indicated precise regiospecific incorporation of precursors, suggesting that surugapyrone A (1) was biosynthesized by type III polyketide synthase. In addition, we speculated that the C-6, $\mathrm{C}-1^{\prime}, \mathrm{C}-2^{\prime}$ and $1^{\prime}-\mathrm{CH}_{3}$ unit was derived from valine, which was reported to be metabolized to isobutyric acid in Streptomyces sp. ${ }^{13,14}$ In other words, the starter unit in the biosynthesis of 1 was an isobutyric acid moiety.

\section{EXPERIMENTAL PROCEDURE}

\section{General experimental procedures}

The melting point of surugapyrone A was measured with Yanaco MP-J3 instrument (Yanaco, Kyoto, Japan). The IR spectrum was recorded with a Jeol FT/IR-550 infrared spectrometer (Jeol, Tokyo, Japan), and the NMR spectra were obtained with a Jeol JMN-ECA-500 spectrometer (Jeol), using tetramethylsilane as the internal standard. High- and low-resolution mass spectra were measured with a Jeol JMS-700 spectrometer (Jeol), using glycerol as the matrix. The UV spectrum was recorded with a Shimadzu UV-160A spectrometer (Shimadzu, Kyoto, Japan). Preparative HPLC was performed using a Jasco 880-PU and Jasco UV-970 apparatus (Jasco, Tokyo, Japan).

\section{Taxonomy of the producing strain}

The strain USF-6280 was isolated from a soil sample collected in Suruga-ku, Shizuoka-city, Japan. The type strain of $S$. coelicoflavus that was used for the comparative study was strain JCM 6918T (T, type strain). This strain was obtained from the Japan Collection of Microorganisms at the RIKEN BioResorce Center (Saitama, Japan).

The morphological characteristics of spore chains were examined by using cells grown on ISP $3 .{ }^{15}$ Cultures were incubated at $28^{\circ} \mathrm{C}$ for 14 days and observed with a scanning electron microscope (Hitachi S-2400; Hitachi, Ibaraki, Japan). Cultural, physiological and biochemical characteristics were determined after a 2 -week incubation period at $28^{\circ} \mathrm{C}$ according to the methods of Shirling and Gottlieb. ${ }^{15}$ The isomers of diaminopimelic acid $\left(\mathrm{A}_{2} \mathrm{pm}\right)$ in the peptidoglycan were determined using the method of Staneck and Roberts. ${ }^{16}$ The biomass used for the analyses were obtained from cultures in yeast extractglucose broth containing $1 \%$ yeast extract and $1 \%$ glucose $(\mathrm{pH} 7.2)$ grown on a rotary shaker. Extraction of genomic DNA extraction, PCR-mediated amplification of the 16S rRNA gene, and sequencing of the PCR products were carried out as described by Nakajima et al. ${ }^{17}$ Multiple alignments of the sequences and construction of a neighbor-joining tree were performed by using the Clustal $\mathrm{X}$ program package. ${ }^{18}$ The GenBank/EMBL/DDBJ accession number for the $16 \mathrm{~S}$ rRNA gene sequence of strain USF-6280 is AB548687.

\section{Measurement of the DPPH radical-scavenging activity}

The ethanol solution of a sample at various concentrations $(1 \mathrm{ml})$ was mixed with a $0.5 \mathrm{~mm}$ DPPH ethanol solution $(0.5 \mathrm{ml})$ and $0.1 \mathrm{M}$ acetate buffer ( $\mathrm{pH} 5.5$;
$1 \mathrm{ml}) .{ }^{19}$ After standing for $30 \mathrm{~min}$, the absorbance of the mixture at $517 \mathrm{~nm}$ was measured. The $\mathrm{ED}_{50}$ value was determined as the concentration of each sample required to give $50 \%$ of the absorbance shown by the blank test.

\section{Labeled compounds}

$\left[1-{ }^{13} \mathrm{C}\right]$ sodium acetate $\left(99\right.$ atom $\left.\%{ }^{13} \mathrm{C}\right),\left[1-{ }^{13} \mathrm{C}\right]$ sodium butyrate (99 atom\% $\left.{ }^{13} \mathrm{C}\right),\left[1-{ }^{13} \mathrm{C}\right]$ sodium propionate $\left(99\right.$ atom $\left.\%{ }^{13} \mathrm{C}\right),\left[1-{ }^{13} \mathrm{C}\right]$ isobutyric acid $(99$ atom $\%{ }^{13} \mathrm{C}$ ) and $\mathrm{L}-\left[\right.$ methyl- $\left.{ }^{13} \mathrm{C}\right]$ methionine $\left(99\right.$ atom $\left.\%{ }^{13} \mathrm{C}\right)$ were purchased from Aldrich and ISOTEC (St Louis, MO, USA).

\section{Administration of labeled compounds to $S$. coelicoflavus strain USF-6280}

Each of the labeled compounds was dissolved in water, and the solution was passed through Minisart (sterile filter, $0.2 \mu \mathrm{m}$; Sartorius, Göttingen, Germany) before it was administered to the $S$. coelicoflavus strain USF-6280. The filtered solution ( $1 \mathrm{ml}$ ) was added to each of the $500-\mathrm{ml}$ flasks containing $100 \mathrm{ml}$ of a medium consisting of glucose, $1 \%$; polypeptone, $0.2 \%$; yeast extract, $0.1 \%$; meat extract, $0.1 \%$; and $100 \mathrm{ml}$ distilled water ( $\mathrm{pH} 7.2$ ). The culture conditions used for all the feeding experiments conducted were identical, except with regard to the amounts of labeled compounds that were added $(50 \mathrm{mg}$ each of $\left[1-{ }^{13} \mathrm{C}\right]$ sodium acetate, $\left[1-{ }^{13} \mathrm{C}\right]$ sodium butyrate and $\left[1-{ }^{13} \mathrm{C}\right]$ isobutyric acid; $25 \mathrm{mg}$ of $\left[1-{ }^{13} \mathrm{C}\right]$ sodium propionate; and $15 \mathrm{mg}$ of $\mathrm{L}-\left[\right.$ methyl $\left.-{ }^{13} \mathrm{C}\right]$ methionine were added to $100 \mathrm{ml}$ of the culture medium. Each of the solutions containing the labeled compounds was added to the culture at $48 \mathrm{~h}$ after inoculation. After cultivation for $120 \mathrm{~h}$ at $30^{\circ} \mathrm{C}$, surgapyrone A (1) was isolated by the same manner as the natural form. Finally, $9.9 \mathrm{mg}, 3.9 \mathrm{mg}, 17.3 \mathrm{mg}, 11.0 \mathrm{mg}$ and $5.6 \mathrm{mg}$ of labeled 1 was obtained from the broths $(10 \times 100 \mathrm{ml}$ or $3 \times 100 \mathrm{ml}$ (only in the case of the feeding expreriment with $\mathrm{L}-\left[\right.$ methyl $\left.{ }^{13} \mathrm{C}\right]$ methionine)) containing $\left[1-{ }^{13} \mathrm{C}\right]$ sodium acetate, $\left[1-{ }^{13} \mathrm{C}\right]$ sodium butyrate, $\left[1-{ }^{13} \mathrm{C}\right]$ sodium propionate, $\left[1-{ }^{13} \mathrm{C}\right]$ isobutyric acid and $\mathrm{L}-\left[\right.$ methyl $\left.-{ }^{13} \mathrm{C}\right]$ methionine, respectively.

1 Abe, N., Murata, T. \& Hirota, A. Novel DPPH radical scavengers, bisorbicillinol and demethyltrichodimerol, from a fungus. Biosci. Biotechnol. Biochem. 62, 661-666 (1998).

2 Abe, N., Murata, T., Yamamoto, K. \& Hirota, A. Bisorbibetanone, a novel oxidized sorbicillin dimmer, with 1,1-diphenyl-2-picrylhydrazyl-radical scavenging activity from a fungus. Tetrahedron Lett. 40, 5203-5206 (1999).

3 Hirota, A., Taki, S., Kawaii, S., Yano, M. \& Abe, N. 1,1-Diphenyl-2-picrylhydrazylradical scavenging compounds from soybean miso and antiproliferative activity of isoflavones from soybean miso toward the cancer cell lines. Biosci. Biotechnol. Biochem. 64, 1038-1040 (2000).

4 Washida, K., Sugiyama, Y., Abe, N. \& Hirota, A. Novel DPPH radical scavengers, demethylbisorbibutenolide and trichopyrone, from a fungus. Biosci. Biotechnol. Biochem. 71, 1052-1057 (2007).

5 Sugiyama, Y., Ito, Y., Suzuki, M. \& Hirota, A. Indole derivatives from a marine sponge-derived yeast as DPPH radical scavengers. J. Nat. Prod. 72, 2069-2071 (2009).

6 Sugiyama, Y. \& Hirota, A. New potent DPPH radical scavengers from a marine-derived actinomycete strain USF-TC31. Biosci. Biotechnol. Biochem. 73, 2731-2734 (2009).

7 Sugiyama, Y., Watanabe, K. \& Hirota, A. Surugapyrroles A and B, two new $N$ hydroxypyrroles, as DPPH radical-scavengers from Streptomyces sp. USF-6280 strain. Biosci. Biotechnol. Biochem. 73, 230-232 (2009).

8 Glavind, J. \& Holmer, G. Thin-layer chromatographic determination of antioxidants by the stable free radical $\alpha, \alpha^{\prime}$-diphenyl- $\beta$-picrylhydrazyl. J. Am. Oil Chem. Soc. 44, 539-542 (1967)

9 Sato, M., Yoneda, N. \& Kaneko, C. Synthesis of 1,3-dioxin-4-ones and their use in synthesis. XI. 2,2-Dimethyl-1,3-dioxin-4-one as a synthetic equivalent of formylketene: synthesis of heterocyclic compounds. Chem. Pharm. Bull. 34, 621-627 (1986).

10 Chu, M., Mierzwa, R., Xu, L., He, L., Terracciano, J., Patel, M., Zhao, W., Black, T. A. \& Chan, T- M. Structure of Sch 419560, a novel $\alpha$-pyrone antibiotic produced by pseudomonas fluorescens. J. Antibiot. 55, 211-214 (2002).

11 Hirota, A., Nemoto, A., Tsuchiya, Y., Hojo, H. \& Abe, N. Isolation of a 2-pyrone compound as an antioxidant from a fungus and its new reaction product with 1,1-diphenyl-2-picrylhydrazyl radical. Biosci. Biotechnol. Biochem. 63, 418420 (1999).

12 Song, L et al. Type III polyketide synthase beta-ketoacyl-ACP starter unit and ethylmalonyl-CoA extender unit selectivity discovered by Streptomyces coelicolor genome mining. J. Am. Chem. Soc. 128, 14754-14755 (2006).

13 Tang, L., Zhang, Y. X \& Hutchinson, C. R. Amino acid catabolism and antibiotic synthesis: valine is a source of precursors for macrolide biosynthesis in 
Streptomyces ambofaciens and Streptomyces fradiae. J. Bacteriol. 176, 6107-6119 (1994).

14 Navarrete, R. M., Vara, J. A. \& Hutchinson, C. R. Purification of an inducible L-valine dehydrogenase of Streptomyces coelicolor A3(2). J. Gen. Microbiol. 136, 273-281 (1990).

15 Shirling, E. B. \& Gottlieb, D. Methods for characterization of Streptomyces species. Int J. Syst. Bacteriol. 16, 313-340 (1966).

16 Staneck, J. L. \& Roberts, G. D. Simplified approach to identification of aerobic actinomycetes by thin-layer chromatography. Appl. Microbiol. 28, 226-231 (1974)
17 Nakajima, Y., Kitpreechavanich, V., Suzuki, K. \& Kudo, T. Microbispora coralline sp. nov., a new species of the genus Microbispora isolated from Thai soil. Int. J. Syst. Bacteriol. 49, 1761-1767 (1999).

18 Thompson, J. D., Gibson, T. J., Plewniak, F., Jeanmougin, F. \& Higgins, D. G. The ClustalX windows interface: flexible strategies for multiple sequence alignment aided by quality analysis tools. Nucleic Acids Res. 24, 4876-4882 (1997).

19 Blois, M. S. Antioxidant determination by the use of a stable free radical. Nature 181, 1199-1200 (1958). 